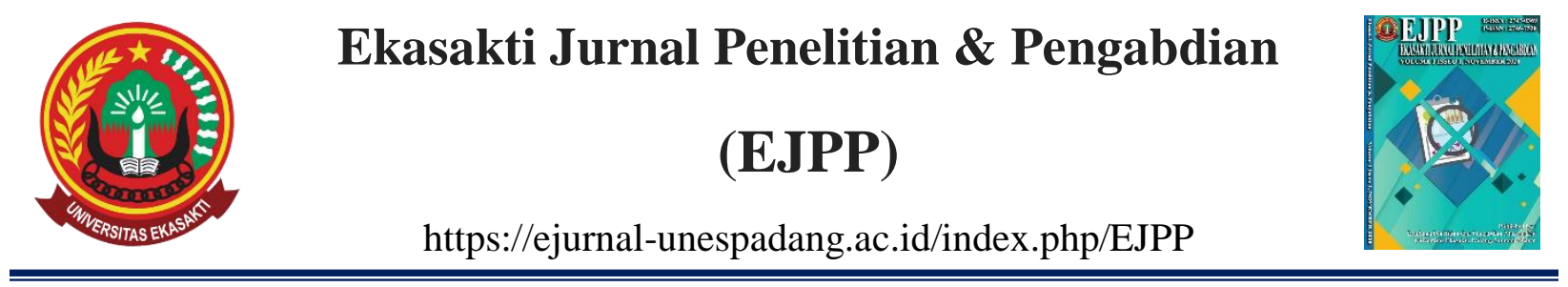

\title{
UPAYA PEMBINAAN KINERJA KEPALA SEKOLAH OLEH PENGAWAS SEKOLAH DI SD BINAAN KECAMATAN PADANG UTARA KOTA PADANG
}

\author{
Misnalitim $^{1}$ \\ ${ }^{1)}$ SD Binaan Kecamatan Padang Utara Kota Padang \\ Email: misnalitim@gmail.com
}

INFO ARTIKEL

Received : 30/10/2021

Revised : :17/11/2021

Publish : :30/11/2021

\section{Kata Kunci:}

Kepala Sekolah, Kinerja, Manajer Utama,

Pengawas.

\begin{abstract}
ABSTRAK
Pendidikan yang berkualitas sangat membutuhkan tenaga kependidikan yang profesional, untuk menjadikan kepala sekolah profesional dan memiliki kemampuan manajerial yang baik, peran pengawas sangat diperlukan dalam membina, membimbing dan mengarahkan kepala sekolah. Seorang kepala sekolah harus memiliki kemampuan memimpin sekolah, terutama kemampuan manajerial. Kepala sekolah adalah pejabat profesional dalam organisasi sekolah yang bertugas mengelola semua sumber daya organisasi dan bekerjasama dengan guru dalam mendidik siswa untuk mencapai tujuan pendidikan dan memahami semua kebutuhan sekolah. Jenis penelitian tindakan pengawas sekolah. Lokasi penelitian di SD binaan Kecamatan Padang Utara Kota Padang berjumlah 16 sekolah. Teknik pengumpulan data observasional dan angket. Teknik analisis data menggunakan persentase. Hasil penelitian menggambarkan bahwa dengan menggunakan metode monitoring dan evaluasi pengawas sekolah dapat meningkatkan kinerja kepala sekolah dalam melaksanakan tugas dan kegiatannya dalam pengelolaan sekolah. Berdasarkan aspek yang dinilai pada siklus I, masih terdapat beberapa indikator yang belum dilaksanakan oleh kepala sekolah. supervisi, penilaian yang dilakukan pada siklus II memberikan hasil yang lebih baik karena masih banyak kepala sekolah yang melakukan kegiatan kinerja manajerial, dalam hal ini kepala sekolah sebenarnya terkadang tidak malas, mereka tidak memahami pekerjaan yang akan mereka lakukan, sehingga mereka memiliki banyak tugas yang harus dilakukan. terkait penilaian kinerja yang belum berjalan dengan baik.
\end{abstract}

Keywords:

Principal, Performance, Main Manager, Supervisor.

\section{ABSTRACT}

Quality education is in dire need of professional education personnel, to make school principals professional and have good managerial skills, the role of supervisors is very much needed in fostering, guiding and directing school principals. A principal must have the ability to lead schools, especially managerial abilities. The principal is a professional official in the school organization who is in charge of managing all organizational resources and collaborating with teachers in educating students to achieve educational goals and understand all school needs. Types of action research school supervisors. The research locations for the fostered elementary schools, North Padang District, Padang City, amounted to 16 schools. Observational data collection techniques and questionnaires. The data analysis technique uses percentages. The results of the study illustrate that using the monitoring and evaluation 
method of school supervisors can improve the performance of school principals in carrying out their duties and activities in school management. Based on the aspects assessed in the first cycle, there are still some indicators that have not been implemented by the school principal. supervision, the assessment carried out in cycle II gave better results because there were many principals who carried out managerial performance activities, in this case the principal was actually not lazy sometimes, they did not understand the work they were going to do, so they had a lot of tasks to do. related to performance appraisal that is not going well.

DOI: https://doi.org/10.31933/ejpp.v2i1.476

\section{PENDAHULUAN}

Kemajuan ilmu pengetahuan dan teknologi di negara maju maupun di negara berkembang sangat ditentukan oleh perkembangan manajemen. Sumber daya manusia (MSDM), sering disebut Human Resource Management yang merupakan foktor dominan di segala bidang, disisi lian perkembangan tersebut tidak seluruhnya berdampak positif. Ilmu pengetahuan dan teknologi dan strategi yang saat ini sebagai pengawas kemajuan umat manusia. Aspek spritual dari kehidupan manusia merupakan kehidupan yang sangat kompleks dalam memenuhi kebutuhan yang bersumber dimensi hubungan manusia dengan tuhan. Peningkatan kualitas manajemen sumber daya manusia yang dilahat dari konsep totalitas kehidupan di atas perlu dilengkapi dengan dimensi kualitas yang bersifat strategis dalam konteks pembangunan seutuhnya yaitu keimanan dan ketakwaan kepada Tuhan yang Maha Esa, profesional, intelektual, disiplin dan efisiensi.

Sejalan dengan tantangan kehidupan global, pendidikan merupakan hal yang sangat penting karena pendidikan salah satu penentu mutu Sumber Daya Manusia. Dimana dewasa ini keunggulan suatu bangsa tidak lagi ditandai dengan melimpahnya kekayaan alam, melainkan pada keunggulan Sumber Daya Manusia (SDM). Di mana mutu Sember Daya Manusia (SDM) berkorelasi positif dengan mutu pendidikan, mutu pendidikan sering diindikasikan dengan kondisi yang baik, memenuhi syarat, dan segala komponen yang harus terdapat dalam pendidikan, komponen-komponen tersebut adalah masukan, proses, keluaran, tenaga kependidikan, sarana dan prasarana serta biaya.

Mutu pendidikan tercapai apabila masukan, proses, keluaran, guru, sarana dan prasarana serta biaya apabila seluruh komponen tersebut memenuhi syarat tertentu. Namun dari beberapa komponen tersebut yang lebih banyak berperan adalah tenaga kependidikan yang bermutu yaitu yang mampu menjawab tantangan-tantangan dengan cepat dan tanggung jawab. Tenaga kependidikan pada masa mendatang akan semakin kompleks, sehingga menuntut tenaga kependidikan untuk senantiasa melakukan berbagai peningkatan dan penyesuaia penguasaan kompetensinya. Pendidikan yang bermutu sangat membutuhkan tenaga kependidikan yang professional, untuk menjadikan kepala sekolah yang profesional dan mempunyai kemampuan manajerial yang baik sangat diperlukan peran pegawas dalam membina, membimbing dan pengarahkan kepala sekolah.

Pengawas adalah salah satu tenaga kependidikan, yang bertugas memberikan pengawasan agar tenaga kependidikan (guru, rektor, dekan, ketua program, kepala sekolah) 
dapat menjalankan tugasnya dengan baik. Pengawas diberi tugas memberikan penilaian dan pembinaan dari segi teknik pendidikan dan administrasi pada satuan pendidikan (Rivai, 2009:817). Tugas pengawas satuan pendidikan tidak hanya melakukan supervisi manajerial kepala sekolah, namun juga membina guru melalui supervisi akademik. Hal ini sejalan dengan Peraturan Menteri Negara Pendayagunaan Aparatur Negara Dan Reformasi Birokrasi Nomor: 21 Tahun 2010 Tentang Jabatan Fungsional Pengawas Sekolah Dan Angka Kreditnya Bab II Pasal 5 Tugas pokok Pengawas Sekolah adalah melaksanakan tugas pengawasan akademik dan manajerial pada satuan pendidikan yang meliputi penyusunan program pengawasan, pelaksanaan pembinaan, pemantauan pelaksanaan 8 (delapan) Standar Nasional Pendidikan, penilaian, pembimbingan dan pelatihan professional Guru, evaluasi hasil pelaksanaan program pengawasan, dan pelaksanaan tugas kepengawasan di daerah khusus.

Sebagai tenaga kependidikan, kepala sekolah membutuhkan bantuan tenaga pengawas, untuk dapat melaksanakan peran masing-masing dengan baik, setiap pemegang peran harus memahami benar apa yang menjadi fungsi perananya, kejelasan tentang peran ini merupakan kondisi prasarat untuk tercapainya harapan tentang sesuatu apa yang menjadi tugasnya. Peran pegawan sangat vital dan penting, pengawas sekolah yang menjadi ujung tombak pejamin mutu pendidikan. Pengawaslah yang diharapkan dapat membimbing kepala sekolah, pengawasan yang diharapkan dapat memberikan masukan saran dan bahkan dapat meningkatkan motivasi dan semangat kerja kepala sekolah.

Pakar manajemen pendidikan mengakui, Kepala sekolah merupakan faktor kunci efektif tidaknya suatu sekolah. kepala sekolah dikatakan kunci karena kepala sekolah memainkan peranan yang sangat penting dalam keseluruhan spktrum pengelolaan sekolah. sebagain manajer pendidikan sekolah yang profesional, kepala sekolah bertanggung jawab sepenuhnya terhadap sukses tidaknya sekolah yang di pimpinya.

Fenoma di lapangan terlihat bahwa pengawas terkadang ditakuti oleh para kepala sekolah dan guru, karena mereka beranggapan bahwa pengawas yang datang kesekolah hanya mendikte kepala sekolah, menakuti-nakuti kepala sekolah, pada hal yang sebenarnya kepala sekolah yang datang hanya menilaia kemampuan kepala sekolah dalam menjalankan kepemimpinannya di sekolah. Seorang kepala sekolah harus mempunyai kemampuan dalam memimpin sekolah terutama kemampuan manajerial Kepala sekolah merupakan seorang pejabat yang profesional dalam organisasi sekolah yang bertugas mengatur semua sumberdaya organisasi dan bekerjasama dengan guru-guru dalam mendidik siswa untuk mencapai tujuan pendidikan serta memahami semua kebutuhan sekolah. Dengan keprofesionalan kepala sekolah, pengembangan profesionalisme guru mudah dilakukan karena sesuai dengan peran dan fungsinyal.

Namun banyak faktor penghambat tercapainya profesionalisme kepala sekolah seperti proses pengangkatannya tidak transparan, kurang memenuhi persyaratan dan kriteria tertentu yang sudah ditetapkan dalam Permendiknas No. 13 tahun 2007, misalnya tidak mempunyai keahlian (kompetensi) manajerial dalam mengelola dan mengembangkan profesionalisme guru, rendahnya mental kepala sekolah yang ditandai dengan kurangnya motivasi dan semangat serta 
kurangnya disiplin dalam melakukan tugas, dan seringnya datang terlambat, wawasan kepala sekolah yang masih sempit, serta banyak faktor penghambat lainnya yang menghambat tumbuhnya kepala sekolah yang profesional untuk meningkatkan kualitas mutu guru dan mutu pendidikan secara nasional.

\section{METODE PENELITIAN}

Prosedur yang digunakan dalam Penelitian Tindakan Sekolah ( PTS) adalah disesuaikan dengan Prosedur Penelitian Tindakan Kelas ( PTK). Menurut Hopkin (1993 : 48) dan Kember (2000 : 26), yaitu sebagai berikut: Dalam penelitian tindakan sekolah ini, langkah pertama yang dilakukan adalah melaksanakan evaluasi terhadap hasil kinerja manejerial kepala sekolah terhadap kepala sekolah binaan di Kota Padang, selanjutnya melakukan pemantauan terhadap pelaksanaan kegiatan kepala sekolah. Diperoleh hasil bahwa dari 16 orang guru di sekolah binaan hanya 5 orang kepala sekolah $(37,5 \%)$ yang telah melaksanakan kegiatan manajerial terutama dalam kegiatan evaluasi diri sekolah dengan menggunakan berbagai pendekatan sedangkan sisanya sebanyak 11 orang guru (68.7\%) masih belum melaksanakan kegiatan manajerial secaa baik, sehingga kegiatan organisasi sekolah kurang berjalan dengan baik.

\section{HASIL DAN PEMBAHASAN}

\section{Siklus I}

\section{Perencanaan}

Sebelum melakukan tindakan terlebih dahulu pengawas menyusun langkah-langkah kerja sesuai dengan prosedur dan penilaian kinerja manajerial kepala sekolah melalui metode monitoring dan evaluasi. Supervise manajerial memiliki focus berupa bidang garapan manajemen sekolah, dalam hal ini aspek yang akan dinilai dalam pelaksanaan supervise manajerial kepala sekolah dalam rangka meningkatkan kinerja kepala sekolah dalam melaksanakan tugas. Aspek yang akan di (1) menetapkan standar untuk mengukur prestasi, (2) melakukan pengukuran prestasi, (3) melakukan analisis data untuk menentukan apakah prestasi memenuhi standar atau tidak, (4) melakukan tindakan perbaikan bila prestasi kurang atau tidak memenuhi standar.

Langkah berikutnya menggunakan metode evaluasi yang akan dinilai oleh pengawas dalam rangka meningkatkan kinerja manajerial kepala sekolah diantaranya (1) untuk mengetahui tingkat keterlaksanan program, (2) untuk mengetahui keberhasilan program, (3) untuk mendapatkan bahan masukan untuk perencanaan berikutnya, (4) untuk memberikan penilaian (judgement) terhadap sekolah, tahap-demi tahap akan dilakukan sebuah tindakan sehingga kinerja kepala sekolah dapat meningkat.

\section{Pelaksanaan}


Pelaksanaan tindakan dilaksanakan pada tanggal 19 Juli 2021, pelaksanaan kegaitan dalam rangka meningkatkan kinerja manajerial kepala sekolah melalui metode monitoring dan evaluasi, pada saat pelaskanaan kegiatan pengawas melengkapi semua dokumen monitoring dan evaluasi Aspek yang akan di (1) menetapkan standar untuk mengukur prestasi, (2) melakukan pengukuran prestasi, (3) melakukan analisis data untuk menentukan apakah prestasi memenuhi standar atau tidak, (4) melakukan tindakan perbaikan bila prestasi kurang atau tidak memenuhi standar.

3. Obervasi

Sebelum melaksanakan observasi pengawas memeriksa berkas dan dokumen kepala sekolah yang berkaitan dengan manajerial. Untuk lebih jelasnya dapat dilihat pada gambar di bawah ini: Pengawas memberikan arahan kepada kepala sekolah dalam melaksanakan manajerial.

Selanjutnya pengawas melakukan eksplorasi bukti fisik dengan menghimpun dan mencatat data sebagai berikut (1) Sekolah mememilki instrumen evaluasi diri, (2) Ada pelaksana kegaitan evaluasi diri dan surat tugas, (3) Terdapat jadwal kegiatan, catatan kegiatan, foto kegiatan dan dokumen laporan pelaksanaan kegiatan, (4) Ada bukti pertemuan mengolah, menyimpulan hasil evaluasi diri dengan fokus utama menggambarkan kekuatan dan kelemahan sekolah, namun belum diperoleh bukti bahwa hasilnya dibahas bersama dengan pemangku kepentingan, ada rekomendasi bersama dengan tim untuk perbaikan tindak lanjut yang dibuktikan dengan adanya rumusan rekomendasi, ada bukti rekomendasi perbaikan mutu yang digunakan untuk perbaikan program.

4. Refleksi

Berdasarkan hasil temuan dapat diberikan catatan itu pengawas menyimpulkan bahwa

a. Terdapat dokumen instrument:

1) jadwal pelaksanaan;

2) Ada data hasil EDS, kesimpulan, dan rekomendasi;

3) Kepala sekolah belum mengolah hasil EDS dengan seluruh pemangku kepentingan dalam memetakan pemenuhan 8 standar melalui EDS;

4) Rekomendasi hasil EDS belum menjadi bahan penyusunan program berikutnya".

b. Selanjutnya pengawas mengisi kolom bukti otentik kualitas kinerja seperti contoh berikut: Dokumen RKJM, RKT/RKAS yang disepakati pemangku kepentingan, tujuan kegiatan terukur, memenuhi skala prioritas, pengalokasian anggaran jelas, meliputi 8 SNP, instrumen evaluasi program dan/atau EDS.

1) Ada instrumen, jadwal pelaksanaan;

2) Ada hasil EDS, kesimpulan, dan rekomendasi;

3) Belum mengolah hasil dengan pemangku kepentingan;

4) Rekomendasi hasil EDS belum menjadi bahan penyusunan program". 


\section{Siklus II}

1. Perencanaan

Hasil penelisian siklus I upaya pengawas dalam meningkatkan kinerja kepala sekolah pada siklus I dapat disimpulkan bahwa masih terlihat beberapa indikator penilaian yang belum dilaksanakan oleh kepala sekolah, tentunya dalam hal ini selaku pengawas akan memberikan monitoring dan evaluasi pada siklus 2 pada aspek yang belum tuntas.

2. Pelaksanaan

Pelaksanaan tindakan siklus II ini dilaksanakan pada tanggal 13 September 2021, dalam hal ini pelaksanaan kegiatan melakukan monitoring dan evaluasi terhadap kegiatan yang dilakukan oleh kepala sekolah dengan dibantu dan dipantau oleh pengawas, pelaksanaan kegiatan yang dilaksanakan melaksanakan supervise manajerial, dan supervise akademik yang dinilai sesuai dengan kriteria penilaian, jika ada kekurangan pada siklus I disempurnakan perbaikan pada siklus II ini, dengan memberikan pengarahan dan bimbingan sesuai dengan metode monitoring dan evaluasi.

3. Obervasi

Instrumen penilaian kinerja kepala sekolah yang digunakan untuk memetakan kinerja kepala sekolah pada 50 item dalam dua dimensi yaitu manajerial dan supervisi. Berdasarkan obervasi yang telah dilaksanakan dengan menggunakan metode monitoring dan evaluasi kinerja kepala sekolah dapat meningkat dengan baik, hal ini tergambar berdasarkan lembar penilaian manajerial dan supervise dari siklus I pada siklus II meningkat secara baik dalam hal ini semua kegiatan dilakukan dengan baik oleh kepala sekolah. Karena pada siklus II penelitian tindakan pengawas ini dihentikan sampai disini tidak dilanjutkan kepada siklus berikutnya.

\section{Refleksi}

Berdasarkan hasil penelitian siklus II inimasih ditemukan beberapa kendala dalam hal ini ketika melaksanakan penilaian kinerja kepala sekolah, terkadang kepala sekolah kurang siap diri dan kurang melengkapi semua persyarakat penilaian yang akan dilaksanakan. Pelaksanaan penilaian kinerja kepala sekolah melalui metode monitoring dan evaluasi cukup efektif digunakan oleh pengawas dalam melaksanakan penilaian kinerja kepala sekolah.

Pengawasan merupakan fungsi manajemen yang berupaya memastikan pelaksanaan pekerjaan sesuai dengan rencana dan ketentuan sehingga tujuan atau target yang telah ditetapkan dapat dicapai. Pengawasan pendidikan bagian dari ilmu administrasi pendidikan yang tidak terlepas dari sistem pemerintahan. Supervise dihadapkan pada kinerja. Tujuan supervisi kepala sekolah dalam hal ini bertujuan untuk memberikan pelayanan kepada kepala sekolah guna mengembangkan mutu kelembagaan pendidikan, memfasilitasi kepala sekolah agar dapat melakukan pengelolaan kelembagaan secara efektif dan efisien.

Seorang pengawas hendaknya memahami betul apa yang menjadi kompetensi Kepala Sekolah di Sekolah. Jika Pengawas mampu memahami bahkan dulunya memang pernah menjadi kepala sekolah maka kompetensi Kepala Sekolah yang akan dinilai pasti sudah memahaminya dengan betul. Bekal kemampuan dalam memahami kompetensi kepala sekolah ini akan menjadi bekal dalam pelaksanaan penilaian kinerja yang harus dilakukan oleh seorang pengawas. Ada 
banyak kompetensi Kepala Sekolah yang setidaknya harus sudah dilaksanakan oleh Kepala Sekolah dalam tugasnya sehari-hari di sekolah yang dimpimpinnya.

Adanya monitoring dan evaluasi dalam mengelola sekolah diperlukan untuk membentuk sekolah yang efektif, sehingga telah ditetapkan suatu standar. Standar pengelolaan adalah standar nasional pendidikan yang berkaitan dengan perencanaan, pelaksanaan, dan pengawasan kegiatan pendidikan pada tingkat satuan pendidikan, kabupaten/kota, provinsi, atau nasional agar tercapai efisiensi dan efektivitas penyelenggaraan pendidikan. Sehingga dalam hal ini, pengelolaan satuan pendidikan akan menjadi tanggung jawab kepala satuan pendidikan.

Sedangkan evaluasi merupakan suatu proses untuk mendapatkan informasi tentang hasil pengelolaan sekolah. Jadi, fokus evaluasi adalah pada hasil pengelolaan. Informasi hasil ini kemudian dibandingkan dengan sasaran yang telah ditetapkan. Jika hasil sesuai dengan sasaran yang telah ditetapkan, berarti pengelolaan sekolah berlangsung efektif. Sebaliknya, jika hasil tidak sesuai dengan sasaran yang telah ditetapkan, maka pengelolaan sekolah dianggap tidak efektif atau gagal.Monitoring dan evaluasi satuan pendidikan memberikan manfaat baik bagi siswa atau peserta pendidikan, pengajar maupun manajemen, serta pengelolaan satuan pendidikan. Dari sisi pendidik, hasil evaluasi dapat digunakan sebagai umpan balik untuk menetapkan upaya upaya meningkatkan kualitas pendidikan.

\section{KESIMPULAN}

Simpulan

Berdasarkan hasil penelitian dan pembahasan yang telah dilaksanakan dapat disimpulkan bahwa dengan menggunakan metode monitoring dan evaluasi pengawas sekolah dapat meningkatkan kinerja kepala sekolah dalam melaksanakan tugas dan kegiatannya dala pengelolaan sekolah. Berdasarkan aspek yang dinilai pada siklus I masih terlihat beberapa indikator yang belum dilaksanakan oleh kepala sekolah

Namun pada siklus II ini berdasarkan kegiatan dan metode yang dilakukan oleh pengawas sekolah, maka terlihat antusias kepala sekolah dalam melaksanakan indikatorindikator yang berkaitan dengan tugas manajerial kepala sekolah dan supervis, penilaian yang dilaksanakan pada siklus II ini memberikan hasil yang lebih baik karena sudah banyak kepala sekolah yang melaksanakan kegiatan kinerja manajerial, dalam hal ini kepala sekolah sebenarnya tidak ada yang malas terkadang, pekerjaan yang akan dikerjakan kurang mereka pahami sehingga banyak tugas-tugas yang berkaitan dengan penilaian kinerja kurang berjalan dengan baik.

\section{Saran}

Berdasarkan kesimpulan di atas dapat diberikan beberapa saran sebagai berikut:

1. Diharapkan kepada kepala sekolah agar lebih meningkatkan kinerja dalam melaksanakan kepamimpinan, sehingga semua kegaitan yang berkaitan dengan kepemimpinan kepala sekolah dapat berjalan dengan baik sesuai dengan harapan dan dapat meningkatkan mutu pendidikan kedepannya 
2. Sebagai tambahan pengalaman bagi pengawas dalam melaksanakan monitoring dan evaluasi dalam penilaian kinerja kepala sekolah

3. Sebagai bahan masukan bagi pengawas sekolah dalam melaksanakan tugas-tugas kepengawasan

4. Sebagai masukan bagi Kementerian Agama dalam meningkatkan kualitas pengawas dalam memberikan pengawasan kepada kepala sekolah dan guru-guru.

\section{DAFTAR PUSTAKA}

AA. Anwar Prabu Mangkunegara, 2000. Manajemen Sumber Daya Manusia. Perusahaan. Bandung: PT Remaja Rosdakarya

Arikunto S, 2006. Prosedur Penelitian Suatu Pendekatan Praktik, Ed Revisi VI,. Penerbit PT Rineka Cipta, Jakarta.

Anoraga, Panji.1992. Psikologi Kerja. Jakarta: Penerbit PT. Rineka Cipta

Danim Sudarwan. 2009. Manajemen dan Kepemimpinan Transformasional Kepala Sekolahan. Jakarta: PT. Rineka Cipta.

Glickman, CD. 1981. Development Supervrlsion Alexandria: Association for. Supervition and Curriculum Development

Erpidawati. 2019. Pengawas Sekolah Smart dan Komunikatif Menyosong Era Revolusi 4.0. Surabaya. Media Guru

Hasibuan, Malayu. 2001. Manajemen Sumber Daya Manusia. Jakarta: BumiAksara.

Mulyasa, E, 2004. Implementasi Kurikulum 2004 Panduan Pembelajaran KBK. Penerbit PT. Remaja Rosdakarya.

Moch. Uzer Usman. 2009. Menjadi Guru Profesional. Bandung: Remaja.

Soedjadi. 2001. Pedoman Penilaian Kinerja. Penerbit Kartika Bina.

Sutisna. 2003. Perilaku Konsumen dan Komunikasi Pemasaran. Cetakan ketiga.

Veithzal,RivaI, dkk. 2009. Manajemen Sumber Daya Manusia UntukPerusahaan (2th ed) Jakarta: Rajawali Pers. 